\title{
AS BRINCADEIRAS DAS CRIANÇAS DE ONTEM E DE HOJE NO CONTEXTO SOCIOCULTURAL
}

\author{
M. F. dos S. SILVA, ${ }^{*}$ A. P. de ANDRADE, M. F. DE P. TORRES, G. C. C. AMORIM \\ Universidade Federal Rural do Semi-Árido - UFERSA \\ micaela_fs55@hotmail.com*
}

Submetido 10/03/2017 - Aceito em 24/07/2017

DOI: $10.15628 /$ holos.2017.5763

\section{RESUMO}

A brincadeira pode ser caracterizada como um elemento conciso que permite o desenvolvimento infantil. Este estudo visa entender as relações das brincadeiras tradicionais com as brincadeiras que envolvem o aparato tecnológico, a partir do contexto sociocultural. Objetivamos identificar os fatores que influenciam no brincar infantil. A pesquisa foi realizada com crianças e adultos da Escola Municipal Paulo Cavalcante de Moura na cidade de Mossoró/RN. Pretendemos desse modo, verificar em que contexto de brincadeiras as crianças de ontem e de hoje se situam. Utilizamos como aporte teórico, estudos de autores que fundamentam a pesquisa, como: Brougère (2010 e 2011), Kishimoto (2001 e 2010), Vygotsky (2007), Piaget (1994), entre outros. O percurso metodológico do estudo baseou-se na pesquisa quanto-qualitativa, em que utilizamos como instrumento de coleta de dados questionários. Para a
\end{abstract}

escolha dos sujeitos que compõe a pesquisa, usamos o método de análise aleatória simples, conforme apresenta Gil (1999). De acordo com os pensamentos dos autores e as análises dos dados da pesquisa, percebemos que não importa o contexto em que vivem, as crianças acabam, de algum modo, brincando. As brincadeiras mais comuns tanto na infância das crianças de ontem, quanto na infância das crianças de hoje, são brincadeiras que sejam desenvolvidas coletivamente. Entendemos que esses tipos de brincadeiras trazem grandes benefícios à infância, pois desenvolvem aspectos motores, cognitivos, afetivos, sociais, entre outros. É importante evidenciar que a brincadeira também é responsável pela propagação da cultura, geração a geração, residindo nesse aspecto à relevância da temática para a educação e para a sociedade.

PALAVRAS-CHAVE: Brincadeiras, Desenvolvimento, Atividade lúdica, Cultura.

\section{CHILD'S GAMES OF YESTERDAY'S AND TODAY'S CHILDREN IN THE SOCIOCULTURAL CONTEXT}

\section{ABSTRACT}

A child's game can be characterized as a simple instrument that allows children development. This research wants to understand, from a sociocultural perspective, the relation between traditional child's games with the newer games that involve technology. We want to identify the main factors that influence the act of children playing. This study was performed with children and adults from the Municipal School Paulo Cavalcante de Moura, in the city of Mossoró/RN. With this research we intend to verify in which game-playing context children of the past and of the present are situated. We employed the following authors for theoretical support: Brougère (2010 and 2011), Kishimoto (2001 and 2010), Vygotsky (2007), Piaget (1994), among others. For this study we followed the
\end{abstract}

quantitative-qualitative research method in which we utilize question sheets as a data-collection tool. We chose the subjects for this research as Gil (1999) suggests, utilizing the simple random analysis method. With this in mind and according to the authors concepts as well as with the results from the analysis of this research, we noted that the context in which the children live makes no difference for they will, somehow, end up playing. The most common children's games either for today's or yesterday's children are the collective ones. We understand that these child's games are highly beneficial to children since they help developing their motor, cognitive, affective and social, among other, skills.

KEYWORDS: Child's game, Development, Playful Activities, Culture. 


\section{INTRODUÇÃO}

O brincar na infância é uma ação espontânea e livre em que as crianças podem se expressar, explorar os objetos, seu corpo e o mundo em que vivem. Por meio das brincadeiras, as crianças identificam características próprias da sua cultura e sociedade, já que estas possuem traços específicos; o que contribui para o desenvolvimento das relações infantis entre criança/criança, criança/adulto e criança/sociedade. Contudo, as discussões acerca da relação que a brincadeira tem com o desenvolvimento infantil e com a cultura são pouco comuns socialmente. Este estudo aborda as brincadeiras na relação entre cultura, sociedade e o desenvolvimento de habilidades importantes na infância.

Este estudo teve como principal finalidade entender as relações das brincadeiras tradicionais com as brincadeiras eletrônicas (ou geracionais) a partir das influências dos contextos socioculturais. Para isso, pretendemos caracterizar brincadeiras tradicionais e brincadeiras que envolvem o aparato eletrônico, evidenciando sua importância no desenvolvimento da criança. Buscamos também identificar fatores que influenciam as brincadeiras no tempo e verificar em que contexto de brincadeiras as crianças de ontem e as crianças de hoje se situam, percebendo se há referências entre elas ou se o tipo de brincadeira é destoante.

O estudo será dialogado com uma pesquisa de caráter exploratório e natureza quantiqualitativa. Segundo Godoy (1995) este tipo de pesquisa se caracteriza por um processo cuidadoso de verificação e ampliação do que já se conhece, procurando entender as perspectivas dos sujeitos da pesquisa. Apesar de diferirem em alguns aspectos, a pesquisa quanti-qualitativa pode reunir aspectos lógicos e intuitivos.

Empregamos a pesquisa bibliográfica para fundamentarmos teoricamente questões pertinentes às temáticas. Este tipo de pesquisa segundo Rampazzo (2002) é comumente introduzida ao suporte investigativo necessita de um apoio bibliográfico para justificar os limites e contribuições da própria pesquisa.

O ambiente escolar reúne uma gama de sujeitos com particularidades, habilidades e características culturais diferenciadas. Os sujeitos desse estudo foram selecionados pelo procedimento de amostragem aleatória simples. O método da amostragem consiste em trabalhar com uma pequena parte dos sujeitos que compõem o universo ou população (referência ao total de habitantes de um local).

Tivemos por finalidade identificar em que contexto de brincadeiras (tradicionais ou eletrônicas) as crianças de ontem e de hoje se situam. Elaboramos oito questões norteadoras para a coleta de dados.

Assim, para iniciarmos nossos estudos e discussões, que tal entendermos melhor sobre concepções, conceitos, temporalidade e influência sociocultural do ato de brincar? 


\section{AS BRINCADEIRAS E A SUA TEMPORALIDADE: QUAL A IMPORTÂNCIA?}

\subsection{A tradicionalidade das brincadeiras de ontem}

Depois do surgimento do capitalismo e da sociedade urbano-industrial, surge adaptações que "resguardam" as crianças de atividades voltadas para os adultos. Arìes apud Lopes, Mendes e Farias (2005) mostra que a partir disso são gerados sentimentos de "paparicação" e "moralização" em relação à criança. A criança e a infância passam a ser vistas por características e fase específicas da vida. O brinquedo e a brincadeira passam a ser especificidades da criança. $O$ autor mostra que essa visão surgiu na Europa, mas que qualquer sociedade está suscetível a ter suas concepções a cerca da criança e da infância. Dessa forma, as discussões sobre esta temática devem levar em consideração os contextos sociais em que se está inserido.

Tanto os brinquedos, quanto as brincadeiras trazem a imagem do seu tempo. Assim, quando há, nesse estudo, uma menção às brincadeiras tradicionais, está se referindo às brincadeiras que os adultos de hoje brincavam nas suas infâncias. As crianças podem viver diferentes infâncias em decorrência das condições sociais, econômicas e culturais, mas há algo em comum entre as crianças, independentemente da infância em que vive: a habilidade criativa. Essa habilidade permite que a criança construa a cultura lúdica, modificando o cenário em que está inserida, compartilhando com outras crianças as brincadeiras. Dessa forma, será construído um diálogo com autores que discutem sobre brincadeiras tradicionais.

De acordo com as ideias de Fernandes (2009), as brincadeiras tradicionais são parte da cultura lúdica. Elas são transmitidas culturalmente, de geração a geração, trazendo elementos e valores. $O$ autor fala que diante do surgimento de brincadeiras que envolvem aparato eletrônico, há uma necessidade de um resgate das brincadeiras tradicionais. As brincadeiras tradicionais defendidas por Fernandes (2009) são baseadas pelas ideias populares, expressadas principalmente pela oralidade e faz parte da cultura popular. Nessa perspectiva, as brincadeiras tradicionais preservam a identidade cultural de um lugar em determinado período histórico.

Há nas brincadeiras particularidades. Para as crianças maiores as regras são facilmente entendidas e respeitadas, diferentemente das crianças menores que ainda não entendem a funcionalidade das regras para as brincadeiras. Nesse sentido Piaget (1994), traz a concepção de desenvolvimento da moral na criança em que é dividido em três fases: a anomia que abrange crianças até 5 anos de idade, que é quando as regras são obedecidas e seguidas, entretanto, são feitas por hábito, não pela moral em si; a heteronomia que abrange crianças até 9 e 10 anos de idade, em que nessa fase, a criança já entende as regras, compreende o que é certo e o que é errado; e a autonomia é a última fase do desenvolvimento da moral, em que há uma legitimação das regras, elas são postas por meio de acordos.

Cardoso (2004) apud Lima (2011) enfatiza a importância do adulto na perpetuação da cultura lúdica, nas brincadeiras tradicionais. Ela notou que são bastante significativas as situações de aprendizagem entre pais e filhos no brincar. A transmissão das brincadeiras de rua, por exemplo, é feita, em parte, dos adultos para as crianças, mas, principalmente, posteriormente, de criança para criança. Lima (2011, p. 05) compreende que a rua é um espaço de sociabilidade e de formação de grupos de crianças, que brincando, construirá a identidade deste lugar. "Ela é um ponto de encontro e local das brincadeiras das crianças, da transmissão e perpetuação dessas praticas lúdicas, de produção da cultura lúdica".

As brincadeiras coletivas, principalmente as das ruas, trazem grandes contribuições para o desenvolvimento da criança. Esse tipo de brincadeira pode exercitar várias capacidades, como a descoberta, a imaginação, a criatividade, a fantasia, o prazer, a noção do real e do irreal e, 
principalmente, os laços afetivos entre as crianças, por meio do desenvolvimento da comunicação e socialização. Pode-se entender, então, que a brincadeira auxilia no desenvolvimento holístico da criança, ou seja, um desenvolvimento conjunto, da totalidade, não apenas em elementos isolados.

Assim, a cultura e a sociedade são meios que permitem que a criança interaja com elementos que servirão de base para as suas brincadeiras. O brincar é uma imagem cultural que acompanha o indivíduo por toda a vida. A cultura lúdica se apropria de elementos da cultura da criança, adaptando-os e aplicando-os nas brincadeiras. A cultura lúdica é construída e enraizada através das brincadeiras.

\subsection{A modernidade das brincadeiras de hoje}

À medida que a sociedade evolui e a cultura muda, as brincadeiras sofrem alterações. $\mathrm{Na}$ contemporaneidade, surge uma gama de brinquedos e brincadeiras que envolvem a tecnologia que se aperfeiçoam cada vez mais rápido. O aparato tecnológico, com o seu incessante crescimento interfere na forma de brincar das crianças. O desenvolvimento social e econômico dos dias atuais é, indiscutivelmente, mais acelerado do que há cerca de meio século. E este é um fator que vai influenciar diretamente na cultura geral, o que automaticamente, influencia na cultura lúdica das crianças. Vale lembrar que as brincadeiras consideradas neste estudo como tradicionais também estão presentes nos dias atuais, entretanto, serão destacadas neste subitem as interfaces das brincadeiras eletrônicas.

Castellón (2007) apresenta dados de uma pesquisa realizada por uma empresa multinacional sobre as brincadeiras infantis no Brasil. A pesquisa mostra que os adultos e as crianças classificam a televisão como uma das brincadeiras mais presentes no dia a dia. Para estes, assistir televisão é brincar.

Contextualizando com a autora, Brougère (2010) expõe que a televisão modifica a cultura e a vida da criança, influenciando, principalmente a cultura lúdica. Entretanto, os autores destoam em alguns aspectos, pois de acordo com Castellón (2007), as brincadeiras estão, além de perdendo a sua essência, se tornando gradualmente mais solitárias. Bougère (2010) concorda com essa afirmação, mas acrescenta que a televisão apresenta grandes contribuições para a brincadeira infantil, trazendo elementos que dificilmente a criança encontraria em outros lugares para subsidiarem o seu brincar.

\footnotetext{
A televisão não se opõe à brincadeira, mas alimenta-a, influencia-a, estrutura-a na medida em que a brincadeira não nasceu do nada, mas sim daquilo com o que a criança é confrontada. Reciprocamente, a brincadeira permite à criança apropriar-se de certos conteúdos da televisão (BROUGÈRE, 2010, p.60).
}

Entende-se também que não é qualquer imagem apresentada na televisão que servirá de suporte para as brincadeiras das crianças, estas devem ser associadas na esfera lúdica infantil. À medida que há uma fragmentação cultural, a televisão tem um valor fundamental no sentido de aproximar, através de sua programação, por uma linguagem comum, crianças de culturas diferentes. Nessa perspectiva, em uma brincadeira coletiva (entre crianças de diferentes culturas), em que as crianças passam a querer se transformar no "super herói" da ficção, entende-se que a televisão serviu de suporte para isso.

O contato com meios eletrônicos permite que a criança desenvolva a coordenação motora fina, ao passo que tem que direcionar comandos para a máquina desenvolver a brincadeira, além de desenvolver a leitura, já que para os comandos da máquina, existem teclas 
específicas, e assim, a criança precisa dominar certos códigos. O raciocínio lógico também é bastante exercitado nesses jogos, pois as crianças devem criar certas lógicas para atingir objetivos. As brincadeiras eletrônicas também possibilitam o desenvolvimento da atenção e da concentração, ao passo que as crianças focam em determinada atividade e se dedicam a ela até cansar, descobrindo nesse processo um contentamento particular interior.

Contemporaneamente, com o crescimento urbano e o desenvolvimento social, alguns fatores contribuem para o "não brincar" das crianças. De acordo com Muller et all (2007), apesar do aumento significativo da violência e do desenvolvimento social, a criança acaba brincando de alguma forma. Contudo, estão cada vez mais restritos ao tempo e ao espaço para estas brincadeiras. Outro fator que para as autoras degrada, de certa forma o brincar, é a ocupação exacerbada das crianças em escolas, oficinas de atividades, cursos etc. Isso ocorre, pois as crianças acabam tendo que desenvolver atividades no mesmo período em que seus pais trabalham, ou seja, acabam "cumprindo" o horário de trabalho que seus pais cumprem. Nesse sentido, as brincadeiras infantis acabam ficando às margens de outras atividades impostas às crianças.

Algo que também pode tolher o brincar infantil está nas inúmeras recomendações que os adultos fazem para as crianças, como "Não suje a roupa", "Não quebre o brinquedo", "Não sente no chão", "Não brinque com meninos", etc.. Isso pode impedir certas ações infantis no decorrer das brincadeiras. Dessa forma, algumas crianças ficam bloqueadas em realizar determinadas brincadeiras. Destoando de uma característica fundamental das brincadeiras, que é a autonomia infantil em escolher e criar sua própria brincadeira. As brincadeiras livres, sem a interferência do adulto também é uma fonte de aprendizagem para as crianças.

Nessa perspectiva, as crianças são induzidas a esse brincar individual, a um brincar cada vez mais solitário. Elas acabam brincando em casa, sem o contato com outras crianças. A sua autonomia agora passa a ser na escolha da programação da televisão, decidindo qual jogo do vídeo game ou computador quer jogar ou qual brinquedo gostaria de ganhar. Àquela socialização e comunicação entre as crianças vão ficando cada vez mis restritos, diminuindo também os laços afetivos que o brincar coletivo pode proporcionar.

Assim, pode-se perceber que as brincadeiras que envolvem o aparato eletrônico atraem bastante à atenção das crianças e também podem contribuir para o desenvolvimento infantil. Entretanto, o contato exagerado com esses jogos, pode favorecer um brincar cada vez mais individualizado, podando a interação entre as crianças.

\section{A TRAJETÓRIA METODOLÓGICA DA PESQUISA}

O estudo foi dialogado com uma pesquisa de caráter exploratório e natureza quantoqualitativa. A escolha deste procedimento foi motivada pela compreensão de que, conforme Neves (1996), os tipos de pesquisa qualitativa e quantitativa não se excluem, dependendo do estudo, eles podem se complementar. Segundo Godoy (1995) este tipo de pesquisa se caracteriza por um processo cuidadoso de verificação e ampliação do que já se conhece, procurando entender as perspectivas dos sujeitos da pesquisa.

Podemos destacar como elementos relevantes da pesquisa qualitativa, a busca pela percepção do contexto em que os pesquisados estão inseridos e melhor compreensão do objeto estudado. Destacamos também que a pesquisa quantitativa tem um caráter objetivo, ela traz constatações estatísticas, baseadas em pressupostos positivistas (NEVES, 1996). Apesar de diferirem em alguns aspectos, a pesquisa quanto-qualitativa pode reunir aspectos lógicos e intuitivos. O referido autor completa dizendo que 


\begin{abstract}
Uma pesquisa pode revelar a preocupação em diagnosticar um fenômeno (descrevê-lo e interpretá-lo); o autor também poderia estar preocupado com explicar esse fenômeno, a partir de seus determinantes, isto é, as relações de nexo casual. Tais pontos de vista não se contrapõem; na verdade complementam-se e podem contribuir, em um mesmo estudo, para um melhor entendimento do fenômeno estudado (p.2).
\end{abstract}

Empregamos a pesquisa bibliográfica para fundamentarmos teoricamente questões pertinentes às temáticas. Este tipo de pesquisa segundo Rampazzo (2002) é comumente introduzida a outros tipos de pesquisa, pois qualquer suporte investigativo necessita de um apoio bibliográfico para justificar os limites e contribuições da própria pesquisa.

O campo de estudo desta pesquisa foi a Escola Municipal Paulo Cavalcante de Moura, situada na cidade de Mossoró/RN. Esta escola atende a cerca de 400 alunos, 17 funcionários e 15 professores. A aproximação com a referida escola foi processual, pois já havíamos realizado outras atividades de pesquisa nesse espaço, algo que estreitou os laços com os componentes da escola.

Para esta pesquisa, utilizamos o método de amostragem aleatória simples, pois através dele é possível fazer uma demonstração e um levantamento de dados com uma pequena quantidade de sujeitos (Gil, 1999).

No caso deste estudo, foi selecionada uma parte reduzida da população. A amostra foi de um subconjunto da população, ou seja, uma parte representativa do todo. A amostragem aleatória simples consiste, conforme Gil (1999), em fazer uma representação numérica dos sujeitos e selecionar de forma casual alguns deles. Para a representação numérica dos sujeitos utilizamos, no caso das crianças, as listas de frequência das turmas do Infantil II " $A$ ", 2음 ano " $A$ ", 4ㅇ ano " $A$ " e 5으 ano " $A$ ". Escolhemos aleatoriamente dois sujeitos de cada turma, pois queríamos uma representação de sujeitos por idade, por exemplo, 5, 7, 9 e 12 anos de idade. Para a seleção dos adultos, utilizamos o livro de frequência dos funcionários os escolhemos da mesma forma da escolha das crianças.

Para afirmar ou não as concepções teóricas estudadas, utilizamos um questionário, cujo principal objetivo é, conforme Gil (1999), o conhecimento de opiniões, interesses e situações vivenciadas. Através deste, temos por finalidade identificar em que contexto de brincadeiras (tradicionais ou eletrônicas) as crianças de ontem e de hoje se situam. Elaboramos oito questões norteadoras para a coleta de dados. Estas questões seguem a mesma linha de investigação, mudando apenas a temporalidade, já que os sujeitos desta pesquisa são as crianças e os adultos (crianças de ontem).

Como algumas crianças ainda não possuíam as habilidades de leitura e escrita, líamos as questões, as crianças respondiam e transcrevíamos as respostas, integralmente. Posteriormente, entramos em contato com os adultos, conversamos brevemente com eles e, diferentemente de como foi aplicado com as crianças, eles mesmos responderam os questionários. Deste modo, os dados da pesquisam foram coletados no âmbito escolar.

\title{
4 A CRIANÇA, O BRINQUEDO, A BRNCADEIRA E A CULTURA LÚDICA
}

\subsection{O brincar no contexto sociocultural das crianças de ontem e hoje}

Para obtenção dos dados necessários para esta pesquisa, foram utilizados dois questionários. Os questionários seguiram a mesma linha de questões, mudando apenas a 
temporalidade das perguntas, já que o objetivo deste estudo é centrado nas brincadeiras da infância, ou seja, as infâncias das crianças dos dias de hoje e as infâncias das crianças de ontem.

Desse modo, pretendeu-se analisar os principais aspectos, relacionados às brincadeiras dessas crianças e perceber se há diferenciação e/ou relação entre elas. Não se pretende exaltar uma em detrimento da outra, almeja entender como se deu/dá a atividade lúdica do brincar culturalmente através dos tempos. Os sujeitos que fizeram parte da pesquisa encontram-se entre cinco anos de idade e cinquenta e cinco anos de idade. Para identificar cada sujeito, o Quadro 1 mostra o delineamento dos agentes da pesquisa com suas respectivas faixas etárias.

\begin{tabular}{|c|c|c|c|}
\hline SUJEITO & IDADE & SUJEITO & IDADE \\
\hline 01 & 5 ANOS & 09 & 38 ANOS \\
\hline 02 & 5 ANOS & 10 & 44 ANOS \\
\hline 03 & 7 ANOS & 11 & 45 ANOS \\
\hline 04 & 7 ANOS & 12 & 46 ANOS \\
\hline 05 & 9 ANOS & 13 & 49 ANOS \\
\hline 06 & 9 ANOS & 14 & 50 ANOS \\
\hline 07 & 12 ANOS & 15 & 54 ANOS \\
\hline 08 & 12 ANOS & 16 & 55 ANOS \\
\hline
\end{tabular}

Quadro 1 - Identificação dos sujeitos e suas respectivas idades

A seguir, serão expostos gráficos demonstrando a vertente central das questões apresentadas às crianças e aos adultos e a representação quantitativa das respostas dos mesmos. Para melhor compreensão será exposta a análise das questões, com um amparo teórico nos autores que discutem as temáticas propostas, respectivamente.

\section{$\square$ Crianças $\square$ Adultos $\quad$ Brincadeiras preferidas}

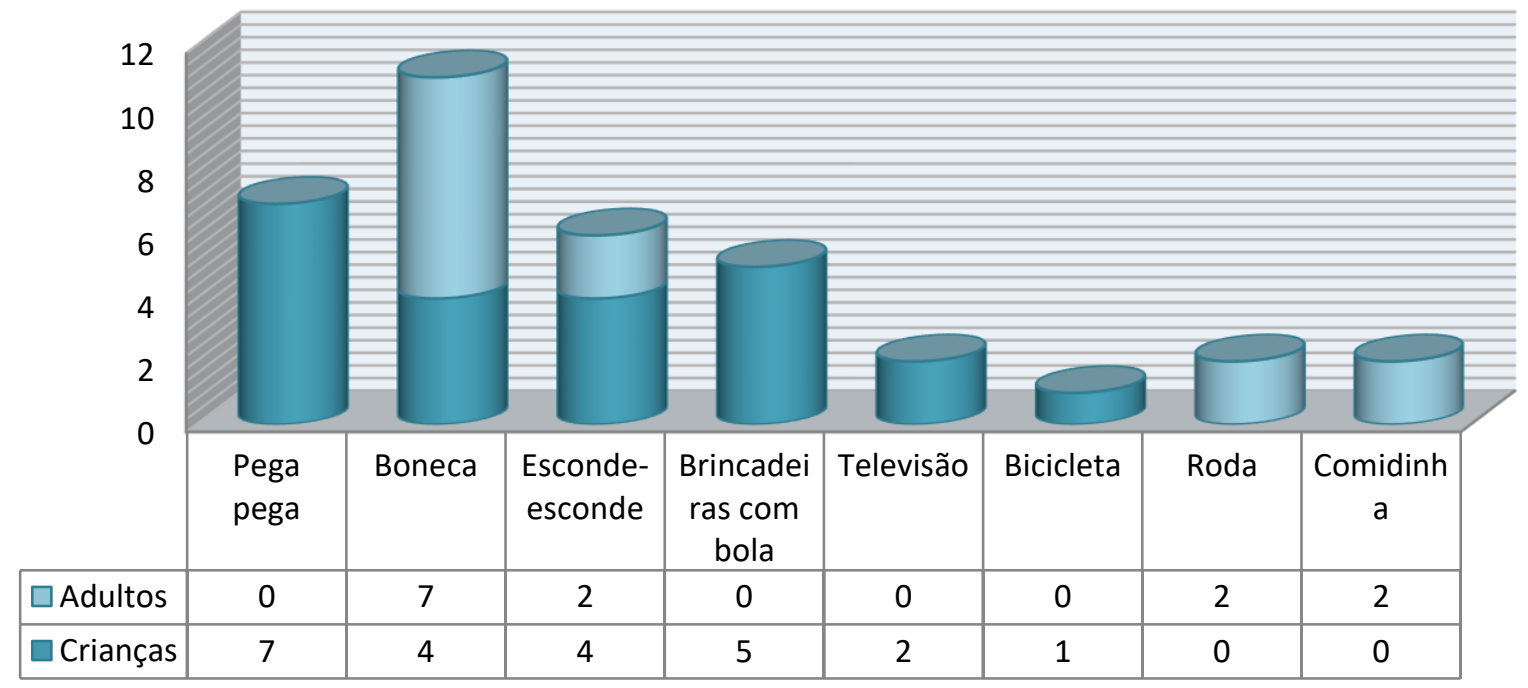

Figura 1. Gráfico de Brincadeiras preferidas. 
Conforme pudemos analisar, na questão sobre as brincadeiras preferidas na infância, os sujeitos de 01 a 08 (Crianças) exibiram eixos comuns em suas respostas. As brincadeiras que são mais corriqueiras no cotidiano destes sujeitos são brincadeiras que propõem uma interação entre as crianças. Pega-pega, esconde-esconde, bicicleta e brincadeiras com a bola que permitem que a criança desenvolva habilidades motoras, cognitivas e relacionais.

Para Fernandes (2009), brincadeiras como esconde-esconde e pega-pega trazem certo caráter tradicional, pois para ele, além de serem realizadas na rua, as principais características dessas brincadeiras são a coletividade infantil e a presença da oralidade, aliada, é claro, com a motricidade. Dialogando com o autor, Kishimoto (2001) fala que as brincadeiras tradicionais são transmitidas de geração a geração. Para a autora, não sabemos de fato quem as criou, entretanto "a cultura não-oficial, desenvolvida especialmente de modo oral, não fica cristalizada" (p.38).

Contudo, pode-se destacar um enfoque destoante na resposta do sujeito 01 que destaca "Ben 10 e os desenhos animados". Nessa perspectiva, a criança considera, como apresenta Castellòn (2007), a televisão e a programação infantil como um tipo de brincadeira. Nos dias atuais, esse tipo de concepção torna-se cada vez mais comum. As crianças passam grande parte do dia em frente à televisão. Brougère (2010) defende a televisão no sentido de que ela é um instrumento a mais nas brincadeiras infantis. A televisão tem, para o autor, uma gama de oportunidades de exploração da brincadeira, traz elementos que dificilmente a criança encontre em outros lugares.

\section{Locais das brincadeiras}

$\square$ Crianças $\square$ Adultos

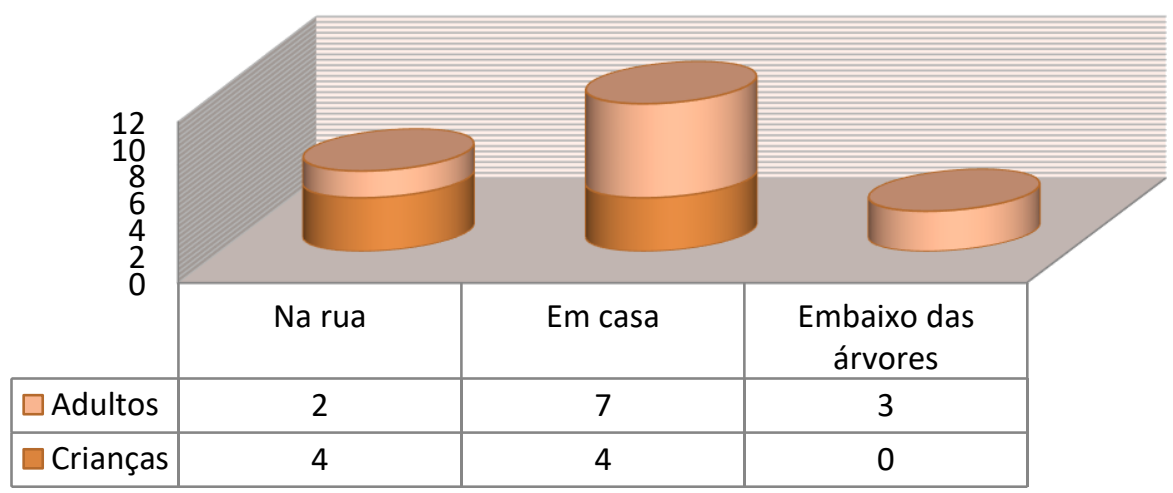

Figura 2. Gráfico de Locais das brincadeiras.

De acordo com as respostas, os sujeitos estão divididos sobre a questão do local de brincar. Vale salientar que "brincar na rua" não é apenas a escolha de um local para realizar a brincadeira, refere-se a um ambiente de socialização entre as crianças, que conforme afirma Lima (2011) é o espaço de transmissão e perpetuação da cultura lúdica.

Nota-se que metade das crianças brincam na rua e a outra metade brincam em casa. $E$ nos adultos, há uma disparidade, em que sete deles em suas infâncias brincavam em casa, apenas dois tinham a prática de brincar na rua. Três deles também brincavam embaixo das árvores, em que se supõe que seja nas redondezas das suas casas.

Os sujeitos 01, 02 e 04 destacam que não brincam na rua por exigência das mães. Para justificar essa questão, o sujeito 01 fala que brincar na rua "é muito perigoso. Passa carro e a criança pode ser atropelada", ou seja, devido ao desenvolvimento urbano e o aumento de veículos, por exemplo, as crianças são privadas de brincar nas ruas. Contudo, uma das crianças 
(08) não brinca na rua apenas por não gostar deste tipo de prática. Assim, Piaget apud Kishimoto (2001, p.32) aborda a brincadeira como um comportamento livre e espontâneo que a criança expressa por um desejo próprio e pelo prazer que esta proporciona.

\section{Brincadeiras individuais ou coletivas}

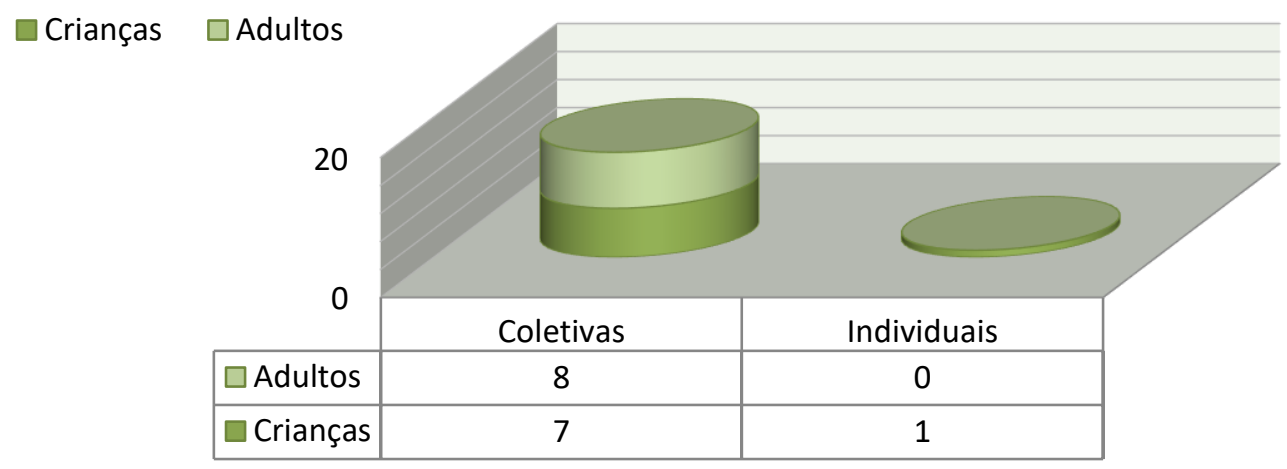

Figura 3. Gráfico de Brincadeiras individuais ou coletivas.

Nesta questão, as brincadeiras coletivas aparecem em uma situação relevante em relação às brincadeiras individuais. A maior parte dos sujeitos explicitou que preferem brincar com outras crianças. Esse tipo de brincadeira permite que as crianças partilhem experiências, desenvolvam a afetividade, construam conhecimentos, ampliem o repertório lúdico, formem a identidade lúdica daquele lugar, entre outros.

Entretanto, de acordo com a pesquisa exposta por Lopes, Mendes e Farias (2005), há crianças, que por diversas influências, nas suas brincadeiras trazem o caráter de "autossuficiência" e independência, em que as crianças acreditam não precisar dos adultos ou de outras crianças em suas brincadeiras para aprenderem algo. Isso, conforme as autoras, pode acontecer devido ao contato exacerbado com determinados desenhos animados, e esta pode ser a postura do sujeito 06, quando fala que prefere brincar sozinho. Podemos fazer algumas associações com a postura egocêntrica. Esta postura para Piaget apud Silva (2006) está presente na infância e serve para marcar o seu ritmo holisticamente. A criança tem uma visão de autossatisfação. É conforme o supracitado autor "sintoma de fraqueza e imaturidade do pensamento da criança" (p.24). Entretanto, esta postura não altera de modo significativo as atividades e a subjetividade da criança.

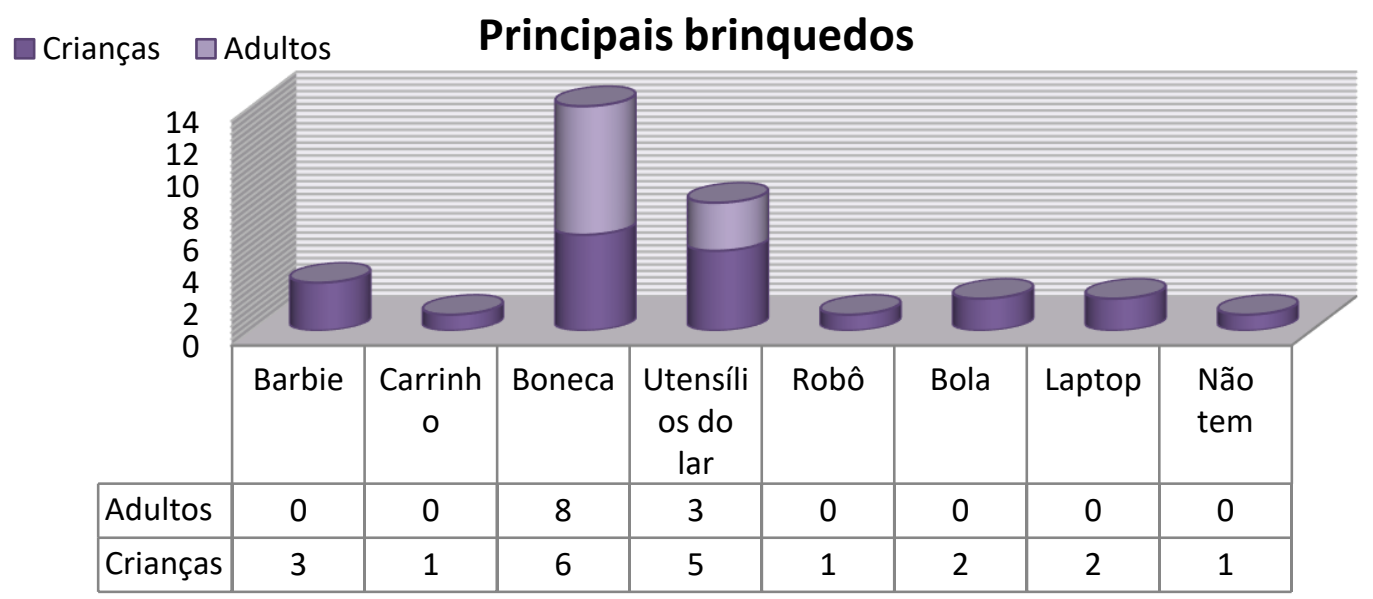

Figura 4. Gráfico de Principais brinquedos. 
Entende-se que tanto o brinquedo, quanto a brincadeira é uma forma de interação entre a criança e a sua realidade. Para Kishimoto (2001), o brinquedo faz representações de diversas realidades. Nesse sentido, o brinquedo permite que a criança entre em contato com reproduções de elementos do seu cotidiano. Ficou evidente que as crianças pesquisadas, de maneira geral, possuem/possuíam diversos brinquedos.

O brinquedo mais comum entre a maioria dos sujeitos é a boneca citado pelos sujeitos $01,03,04,05,06,08,09,10,11,12,13,14,15$ e 16 . A relação da criança com a boneca, na maior parte dos casos, remete a relação social de mãe e filha, perpassando a ideia de cuidar. Kishimoto (2001) discute essa temática mostrando que através dos brinquedos como as bonecas permitem várias formas de brincar, desde a manipulação do objeto. Entretanto, as bonecas citadas pelos sujeitos são diferentes, pois os adultos falam que suas bonecas eram feitas de pano por suas mães ou tias, como fala o sujeito 16 que "gostava mais das minhas bonecas de pano feitas pela minha tia", algo que as tornavam exclusivas. Percebe-se que, nos dias atuais isso é diferente. As bonecas estão imersas num processo de produção em larga escala, o que padroniza esse brinquedo, deixando o caráter exclusivista que este tinha antigamente.

Muitas vezes o mercado capitalista designa esse brinquedo somente para as meninas, ou seja, dissemina uma visão cultural machista de quem cuida do bebê (representado pela boneca) é apenas a mãe. Nesse sentido, há uma padronização dos brinquedos masculinos e femininos. 0 carrinho aparece como brinquedo masculino e este é citado como principal brinquedo do sujeito 02. Na perspectiva das relações, entre os brinquedos citados pelos sujeitos podemos destacar os utensílios do lar, como sofá, cadeira e panelinha, os aproximando da realidade, que aparecem tanto nas respostas das crianças dos dias de hoje, quanto nas crianças de antigamente. Estes brinquedos antigamente, assim como a boneca, eram fabricados artesanalmente, como cita o sujeito 12 que brincava com "móveis de caixa e de lata de óleo".

A Barbie, nas mais variadas versões, é citada por três sujeitos (01, 03 e 06). Esta, por sua vez, traz marcas culturais diferenciadas das do cotidiano dos sujeitos, pois é um estereótipo de "mulher americana" e uma padronização de corpos longilíneos e magros. Este brinquedo é propagado há certo tempo pela mídia e pelo mercado, trazendo verdadeira fascinação nas meninas. Entretanto, não podemos subtrair o caráter lúdico que a boneca Barbie carrega, pois ela é um dos meios que favorece a brincadeira, desenvolvendo a imaginação, criatividade e a representação social através de suas variadas apresentações.

Outros brinquedos citados pelos sujeitos são a bola, o robô e o laptop. O primeiro é destacado por dois sujeitos (02 e 06). Estas brincadeiras com a bola são importantes no desenvolvimento motor infantil, pois conforme Santos e Damasceno (2010), elas desenvolvem habilidades fundamentais para a criança, como correr, pular, arremessar, entre outros. O robô e - laptop são brinquedos mais modernos, entretanto o primeiro é citado apenas por uma criança (sujeito 02) e o segundo por duas delas (sujeitos 05 e 06), o que indica que os sujeitos pesquisados possuem brinquedos que caracterizam seu tempo.

Entende-se, nessa perspectiva que o brinquedo carrega características do seu tempo, pois dificilmente, as crianças de ontem (os adultos de hoje) teriam o contato com brinquedos eletrônicos. De forma geral, os sujeitos se encontram na perspectiva de utilização de brinquedos tradicionais, ou seja, àqueles que perpassam desde o tempo das crianças de ontem. Todavia, o sujeito 07 fala que não possui nenhum brinquedo, fator diferenciado entre as demais respostas. 
$\square$ Criança $\square$ Adulto $\quad$ Brinquedos ou brincadeiras de rua

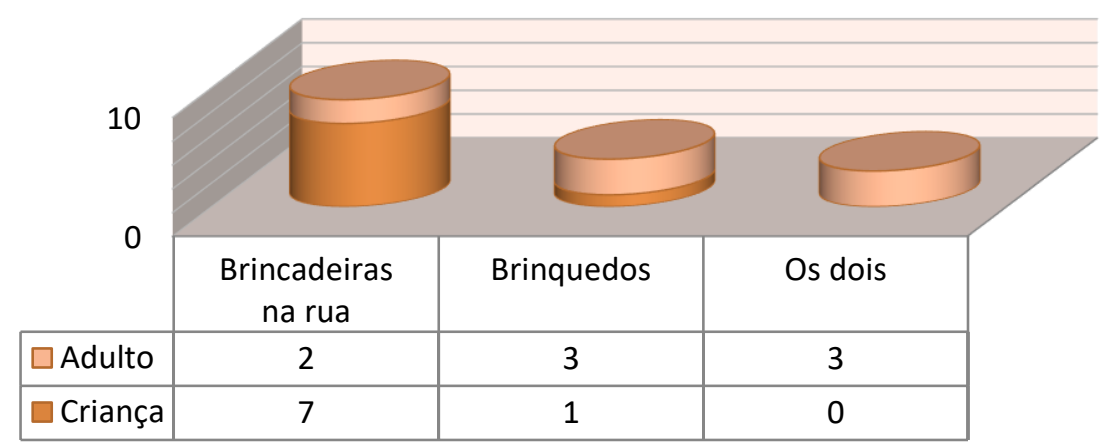

Figura 5. Gráfico de Brinquedos ou brincadeiras de rua.

Pôde-se perceber que maior parte dos sujeitos preferem brincadeiras na rua. Assim como na questão 2, as crianças, mais uma vez demonstraram esse desejo de brincar na rua acompanhadas por outras crianças. A rua é considerada um espaço de encontros entre as crianças, onde pode haver a perpetuação da cultura do local e construção coletiva da cultura lúdica infantil. Pode-se destacar, entre outros fatores, as brincadeiras na rua permite que as crianças se comuniquem, fortaleçam os laços afetivos de amizade e companheirismo.

Já os sujeitos 12, 15 e 16 expuseram que gostava tanto de brincar com os seus brinquedos quanto com outras crianças na rua. Apenas os sujeitos 06, 11, 13 e 14 preferem brincar com os seus brinquedos. Podemos perceber, nesse sentido, que a cultura lúdica é construída e enraizada por meio das brincadeiras e das relações infantis com o brinquedo. Trata-se, assim, segundo Brougère (2011) de uma interação social, através tanto pelo contato com o brinquedo, quanto pelo contato com situações imaginárias. Essa cultura não passa de um indivíduo para outro, ela é construída individual e coletivamente. Sofrendo fortes influências também da macrocultura.

\section{Brincadeiras com jogos eletrônicos}

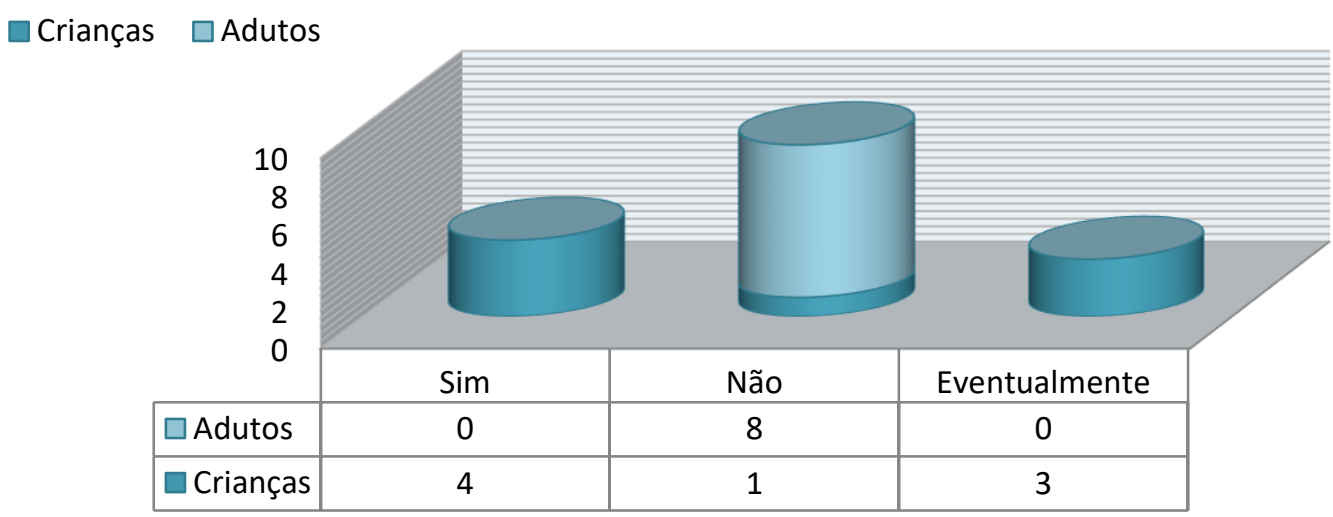

Figura 6. Gráfico de Brincadeiras com jogos eletrônicos.

Nesta questão os sujeitos $01,02,03,05,06,07$ e 08 brincam ou já brincaram com os jogos eletrônicos. Os principais meios dos jogos eletrônicos utilizados pelas crianças são o vídeo game, o computador e o celular. 0 sujeito 02 e 08 destacam que brincam com esses jogos diariamente: "brinco mais do que com os meus brinquedos" (sujeito 02) "brinco todos os dias com os joguinhos do celular" (sujeito 08). 
Unanimemente, os adultos responderam que nas suas infâncias não tiveram nenhum contato com jogos ou brincadeiras eletrônicas. De acordo com a análise, pode perceber que apesar de as crianças dos dias atuais brincarem com esses jogos, eles não o faz com frequência, isto é, essas brincadeiras não fazem parte do seu dia-a-dia.

Entretanto, Lima (2011) mostra que apesar dos avanços tecnológicos, principalmente no brinquedo, há ainda no Brasil alguns lugares que as práticas lúdicas tradicionais são presentes. Essas brincadeiras coexistem juntamente com práticas lúdicas contemporâneas. Uma pesquisa realizada em uma rua na cidade de Fortaleza/CE, pelo referido autor, mostra a relação entre o tradicional e o contemporâneo, em que as crianças brincam tanto com o peão, quanto com a beyblade. Este último é uma versão aperfeiçoada do peão e, ainda assim as duas versões continuam presentes no cotidiano das brincadeiras nessa localidade.

Nessa perspectiva, as brincadeiras mais comuns para as crianças, tanto as de hoje, quanto as de ontem, são brincadeiras com brinquedos sem aparato eletrônico e brincadeiras que supõem a participação e interação de outras crianças.

\section{CONSIDERAÇÕES FINAIS}

Estudar o universo lúdico nos oportunizou perceber aspectos muitas vezes esquecidos ou pouco conhecidos que estão impregnados nas relações do brincar infantil. Entender as brincadeiras como algo que serve para "passar o tempo" ou apenas para entreter as crianças, é um conhecimento superficial. Essa atividade lúdica é responsável por desenvolver habilidades que seguirão o sujeito até a fase adulta, alterando significativamente diversas atitudes/posturas.

Percebemos que independente do local e da cultura em que está introduzida, a criança acaba, de alguma forma, brincado. Entre as crianças podem existir várias infâncias, pois isso decorre das condições sociais e econômicas do contexto cultural de cada criança. E independentemente da infância, as crianças carregam consigo o caráter criativo.

Pudemos entender as brincadeiras como um dos principais elementos culturais. E como tal, ela é capaz de trazer traços específicos de diversas sociedades. É através dela que as crianças desenvolvem e incrementam a cultura infantil ou cultura lúdica.

Por intermédio das brincadeiras, as crianças podem se expressar, aprender uma série de novas informações, e desenvolver aspectos cognitivos, motores, psicológicos, sociais, afetivos etc. Nesse processo lúdico é que a criança inicia a formação da sua personalidade, ou seja, a relação com a brincadeira e com outras crianças vai interferir diretamente nesse aspecto subjetivo de cada pessoa.

Assim, concluímos, inicialmente, a partir de reflexões acerca da brincadeira e análise de dados que esta é complexa. Envolve aspectos que se relacionam diretamente ao desenvolvimento de habilidades infantis e está em constante conexão com a cultura e a sociedade.

As brincadeiras transmitem e constroem de tempos em tempos, traços históricos que são repassados, geração a geração. Nesse sentido, finalizamos as nossas reflexões sobre as vertentes diretas do "chão" da sala de aula e da sociedade transfigurados no ato de brincar (que se constitui em um objetivo no contexto do RCNEI). Esperamos que este trabalho subsidie novas discussões e abra portas para outros diálogos acerca da vida e da escola, pois essa relação uníssona é que alimenta o trabalho da educação. 


\section{REFERÊNCIAS}

BROUGÈRE, G. (2010). Brinquedo e Cultura. São Paulo: Cortez.

BROUGÈRE, G. (2011). A criança e a cultura lúdica. In: KISHIMOTO, Tizuko Morchida. O brincar e suas teorias. São Paulo: Cengage Learning.

CASTELLÒN, L. (2007). Como brincam nossas crianças. Revista Isto É. 10 (46). 23-40.

FERNANDES, S. (2009). Brincadeiras Tradicionais. Recuperado em 15 de Fevereiro de 2012 de www.ebah.com.br/content/ABAAAAN.../brincadeiras-tradicionais.

GIL, A. C. (1999). Métodos e técnicas de pesquisa social. 5. ed. - São Paulo: Atlas.

GODOY, A. S. (1995). Introdução à pesquisa qualitativa e suas possibilidades. Revista de Administração de Empresas. São Paulo. 35 (2). 57 - 63.

KISHIMOTO, T. M. (2010). Brinquedos e brincadeiras na Educação Infantil. São Paulo: Cortez.

KISHIMOTO, T. M. (2001) O jogo e a educação. In: KISHIMOTO, Tizuko Mochida. Jogo, brinquedo, brincadeiras e a educação. - 5a Edição. São Paulo: Cortez.

LIMA, F. J. I. de. (2011 Março). Práticas culturais lúdicas em jogo: tradição e atualidade nas brincadeiras da rua. In: XI CONGRESSO LUSO AFRO BRASILEIRO DE CIÊNCIAS SOCIAIS. Universidade Federal da Bahia: PAF I e II, Salvador, 01 - 12.

LOPES,K. R., MENDES,R. P. \& FARIA, V. L. B. de. (2005) Coleção Proinfantil - Livro de estudo: Módulo II - Secretaria de Educação Básica. Secretaria de Educação a Distância,/- Brasília: MEC.

MÜLLER, V. R. et al. (2007). O brincar das crianças: aproximações às culturas infantis. Buenos Aires: Revista Digital. Recuperado em 27 de novembro de 2011 em www.pca.uem.br 11(104).

NEVES, J. L. (1996). Pesquisa qualitativa - características, uso e possibilidades. Cadernos de pesquisa em administração. São Paulo. 1 (3).

PIAGET, J. (1994). O juízo moral na criança. Tradução: Elzon Lenardon. São Paulo: Summus.

RAMPAZZO, L. (2002). Metodologia Científica - para alunos de graduação e pós-graduação. São Paulo: Editora Loyola.

SANTOS, C. R. dos. \& DAMASCENO, M. L. (2010). Desenvolvimento motor: diferenças do gênero e os benefícios da prática do futsal e ballet na infância. Revista Hórus. São Paulo. 4(2), 177187.

SILVA, J. M. (2006). Pensamento e Linguagem em Lev Vygotski e Jean Piaget. Recuperado em 12 de Outubro de 2012 em bocc.uff.br/pag/silva-jose-manuel-pensamento-linguagem.pdf.

VYGOTSKY, L. S. (2007). A formação social da mente: o desenvolvimento dos processos psicológicos superiores. Org. Michael Cole ET all. - 7ạ edição. - São Paulo: Martins Fontes. 